\title{
Ehrlichiose monocítica eqüina no Rio Grande do Sul: aspectos clínicos, anátomo-patológicos e epidemiológicos ${ }^{1}$
}

\author{
Helen S. Coimbra ${ }^{2}$, Cristina G. Fernandes ${ }^{3}$, Mauro P. Soares ${ }^{3}$, Mário Carlos A. \\ Meireles $^{2}$, Roberto Radamés ${ }^{2}$ e Luiz Filipe D. Schuch ${ }^{4 *}$
}

\begin{abstract}
Coimbra H.S., Fernandes C.G., Soares M.P., Meireles M.C.A., Radamés R. \& Schuch L.F.D. 2006. [Equine monocytic Ehrlichiosis in Rio Grande do Sul: clinical, pathological and epidemiological aspects.] Ehrlichiose monocítica equïina no Rio Grande do Sul: aspectos clínicos, anátomo-patológicos e epidemiológicos. Pesquisa Veterinária Brasileira 26(2):97-101. Laboratório de Doenças Infecciosas, Faculdade de Veterinária, Universidade Federal de Pelotas, Campus Universitário, Pelotas, RS 96010-900, Brazil. E-mail: bitoxu@ig.com.br

A spontaneous outbreak of equine monocytic Ehrlichiosis (EME) is described. The disease occurred from November 2001 to February 2002 on a farm in the municipality of Arroio Grande, located at the western edge of the Mirim Lake, state of Rio Grande do Sul. Out of 50 horses 13 were affected and 6 died. The morbidity was $26 \%$ and the mortality $46.1 \%$. The affected horses were $1-5$ years old. The most important clinical sign was a profuse acute diarrhea. At necropsy of a horse that died with clinical signs of the disease, the main alterations were characterized by hemorrhagic areas of the mucosa of the large intestine with liquid contents, and congested and hemorrhagic areas alternating with normal areas as well as nodules with purulent secretion in the mucosa of the small intestine. The histological changes were characterized by moderate mononuclear infiltration of the mucosa, characterizing a lympho-histiocytic enteritis with predominance of macrophages. In the jejunum and ileum, related to the invagination of crypts and villi, a granulomatous enteritis was observed. To confirm the diagnosis of infection by Neorickettsia (Ehrlichia) risticii, blood samples of seven affected horses were taken and a polimerase chain reaction (PCR) was performed. Three tested blood samples were positive (42.8\%) with observation of a band of $529 \mathrm{pb}$ characteristic of N. risticii.
\end{abstract}

INDEX TERMS: Neorickettsia (Ehrlichia) risticii, equine monocytic Ehrlichiosis.

RESUMO.- Descreve-se um surto natural de Ehrlichiose monocítica eqüina (EME) ocorrido nos meses de novembro/2001 a fevereiro/2002, em uma propriedade no município de Arroio Grande, localizado à margem oeste da Lagoa Mirim, Rio Grande do Sul. De um total de 50 equïnos, 13 foram afetados pela enfermidade e seis morreram. A morbidade foi de $26 \%$ e a letalidade $46,1 \%$. Os animais acometidos tinham idades entre um e cinco anos e o quadro clínico mais evidente foi o desenvolvimento de diarréia aguda aquosa e profusa. Um dos animais que morreram

\footnotetext{
${ }^{1}$ Recebido em 23 de fevereiro de 2005.

Aceito para publicação em 6 de dezembro de 2005.

2 Laboratório de Doenças Infecciosas, Depto Veterinária Preventiva, Faculdade de Veterinária, Universidade Federal de Pelotas (UFPel).

${ }^{3}$ Laboratório Regional de Diagnóstico, Faculdade Veterinária, UFPel.

${ }^{4}$ Laboratório de Doenças Infecciosas, Depto Veterinária Preventiva, Faculdade de Veterinária, UFPel, Campus Universitário s/n, Pelotas, RS 96010900. *Autor para correspondência. E-mail: bitoxu@ig.com.br
}

foi necropsiado e as lesões observadas localizavam-se principalmente no trato intestinal, caracterizando-se por intestino grosso com conteúdo líquido e áreas hemorrágicas difusas na mucosa. Em todo o segmento de intestino delgado observaramse áreas com mucosa congesta e hemorrágica alternadas com áreas de mucosa normal. Na mucosa de jejuno e íleo observouse a presença de nódulos contendo secreção purulenta. Os achados histológicos em todo trato intestinal caracterizaram-se pela presença de discreto infiltrado mononuclear restrito a mucosa do órgão, caracterizando uma enterite linfo-histiocitária com predominância de macrófagos. No jejuno e íleo também havia regiões com lesões granulomatosas na lâmina própria, relacionadas a invaginações das criptas das vilosidades intestinais. Para o diagnóstico da infecção por Neorickettsia (Ehrlichia) risticii amostras de sangue de sete eqüinos doentes foram testados pela reação em cadeia da polimerase (PCR), resultando em três amostras positivas $(42,8 \%)$ com a formação de uma banda de $529 \mathrm{pb}$, típica para N. risticii. 
TERMOS DE INDEXAÇÃO: Neorickettsia (Ehrlichia) risticii, Ehrlichiose monocítica equiina.

\section{INTRODUÇÃO}

A Ehrlichiose monocítica eqüina (EME) é uma doença infecciosa não contagiosa causada pela Neorickettsia (Ehrlichia) risticii. Esta enfermidade foi evidenciada no Estado de Maryland, Estados Unidos, em 1979, em região próxima ao Rio Potomac, sendo conhecida como a febre do cavalo de Potomac (Potomac horse fever) (Rikihisa \& Perry 1985). Em outros países, como Canadá, França, Itália, Venezuela, Índia e Austrália, a EME foi evidenciada através de testes sorológicos (Palmer et al.1986, Breider \& Henton 1987, Rikihisa 1998).

A Ehrlichiose monocítica equiina tem caráter endêmico e sazonal, com a ocorrência dos casos em áreas alagadiças, às margens de rios e lagos, nos meses mais quentes do ano (Atwill et al. 1992). No litoral sul do Rio Grande do Sul e no Uruguai, casos compatíveis com EME foram identificados em propriedades localizadas próximo às Lagoas Mirim e Mangueira, principalmente nos municípios de Santa Vitória do Palmar, Rio Grande e Arroio Grande (Coimbra et al. 1999, Dutra et al. 2001).

Todos os eqüinos são suscetíveis à doença, sendo que animais transportados para áreas endêmicas parecem ser suscetíveis a infecções mais graves do que aqueles nascidos nestas áreas (Atwill et al. 1992, Dutra et al. 2001). A transmissão oral é a principal forma de transmissão da $N$. risticii.

Com base na sequiência do gene que codifica para a porção $16 S$ do RNA-ribossômico verificou-se uma forte identidade genética entre $N$. risticii e outras riquétsias como a Neorickettsia (Ehrlichia) sennetsu, Neorickettsia helminthoeca e o agente do Stellantchasmus falcatus (Agente SF) que sabidamente apresentam um padrão de transmissão oral intermediado por trematódeos. Dessa forma, foi sugerido que $N$. risticii acompanha este mesmo padrão de transmissão envolvendo trematódeos aquáticos (Wen et al. 1996, Barlough et al. 1998, Rikihisa, 1998, Kanter et al. 2000, Pusterla et al. 2000, Dumler et al. 2001). Caramujos existentes em regiões de ocorrência de EME nos Estados Unidos foram identificados como portadores de N. risticii, assim como as cercárias albergadas por eles, sendo considerados vetores desta riquétsia (Barlough 1998, Kanter et al. 2000, Pusterla et al. 2000). No Rio Grande do Sul, foram identificados caramujos do gênero Heleobia que albergavam cercárias do tipo Parapleurolophocercous cercariae como portadores de N. risticii (Coimbra 2003).

Os animais com EME podem desenvolver diarréia, febre, desidratação e anorexia, com variação do quadro clínico de leve a severo terminando com a morte dos animais (Rikihisa \& Perry 1985, Ziemer et al. 1987). As alterações patológicas mais consistentes de EME são a presença de conteúdo fluído no cólon maior e ceco, e áreas de hiperemia com extensão e distribuição variáveis na mucosa do órgão. $O$ conteúdo presente no intestino delgado varia de consistência mucosa a aquosa, com áreas da mucosa apresentando hiperemia e congestão, podendo ocorrer áreas com lesões intercaladas por áreas sem lesão (Cordes et al. 1986). As alterações microscópicas revelam uma enterocolite linfohistiocitária, caracterizada por congestão, necrose epitelial superficial e infiltrado inflamatório mononuclear na lâmina própria e submucosa do ceco e cólon maior (Dutra et al. 2001).
Os objetivos deste trabalho foram relatar um surto natural de EME em animais recém introduzidos em uma área endêmica e caracterizar aspectos epidemiológicos, clínicos e descrever a patologia, bem como confirmar o diagnóstico pela técnica de PCR.

\section{MATERIAL E MÉTODOS}

\section{Epidemiologia e sinais clínicos}

O surto foi estudado em uma propriedade localizada no município de Arroio Grande, margem oeste da Lagoa Mirim, Rio Grande do Sul. Através de visitas a propriedade, foram obtidos dados epidemiológicos. Exames clínicos foram realizados de animais apresentados pelo proprietário como enfermos. Coletou-se sangue em tubo estéril com anticoagulante (EDTA $10 \%$ ) desses animais para a pesquisa de $N$. risticii pela técnica de PCR.

\section{Patologia}

Necropsia de um dos animais que morreram foi realizada, coletando-se os órgãos das cavidades abdominal e torácica que foram fixados em formol tamponado a $10 \%$, processados pelas técnicas de rotina e corados pela hematoxilina-eosina para estudo histológico das lesões. Para identificar a presença de $N$. risticii nas células do intestino grosso, fragmentos de $0,5 \mathrm{~cm}$ foram fixados em glutaraldeído, incluídos em resina e cortes semifinos foram submetidos à coloração de azul de metileno.

\section{Diagnóstico - Reação em cadeia da polimerase (PCR)}

Extração do DNA. Para pesquisa de $N$. risticii por PCR, primeiramente foi realizada a extração do DNA. O sangue coletado foi centrifugado durante 10 minutos a $3000 \mathrm{rpm}$ (micro-centrífuga NT 80, Nova Técnica) para promover a separação dos elementos do sangue. Após a centrifugação, o plasma foi descartado e a capa flogística foi coletada e acondicionada em um recipiente estéril, contendo $2 \mathrm{ml}$ de PBS (pH 7,2). Após, 300ml deste material, foram colocados em tubo tipo "Eppendorff" com $300 \mu \mathrm{l}$ de água ultrapura estéril, durante 10 minutos em temperatura ambiente com a finalidade de lisar as hemácias restantes no meio. $O$ material foi centrifugado e o sedimento foi ressuspenso em tampão de extração SE (EDTA 0,1 M ( $\mathrm{pH} \mathrm{8,0),} \mathrm{NaCl} 0,15 \mathrm{M})$, adicionado de proteinase $\mathrm{K}(50 \mathrm{mg} / \mathrm{ml})$. A digestão da proteína foi realizada durante 10 minutos a $56{ }^{\circ} \mathrm{C}$. A extração do DNA foi realizada pelo método fenol-clorofórmio. Após, o sedimento obtido foi seco em temperatura ambiente e ressuspenso em $100 \mathrm{ml}$ do tampão TE (Tris $\mathrm{HCl} 10 \mathrm{mM}(\mathrm{pH} 7,4)$, EDTA $1 \mathrm{mM} \mathrm{pH} \mathrm{8,0)}$ e acondicionado a $-20^{\circ} \mathrm{C}$ até ser utilizado.

Nested PCR. A PCR foi direcionada para amplificar uma porção de $529 \mathrm{pb}$ do gene que codifica para o fragmento $16 \mathrm{~S}$ do RNAribossômico da $N$. risticii. Foi realizado em duas etapas (nested PCR), utilizando-se um par de oligonucleotídeos (ER3: ATTTGAGAGTTTGATCCTGG e ER2: GTTTTAAATGCAGTTCTTGG) na primeira etapa e, na segunda etapa, outros dois oligonucleotídeos (ER3A: CTAGCGGTAGCGTTAAC; ER2A: CACACCTAACTTACGGG) que amplificavam um fragmento interno ao primeiro. Foram montadas reações com volume final de $50 \mu \mathrm{l}$ por amostra, tendo como DNA alvo na primeira etapa $3 \mu \mathrm{l}$ do DNA extraído de cada animal suspeito e, na segunda, $1 \mu 1$ do DNA amplificado na primeira etapa.

Os dois PCR foram realizados sob as mesmas condições de tempo e temperatura. Primeiramente, uma desnaturação inicial de 5 minutos a $94^{\circ} \mathrm{C}$, após 35 ciclos de desnaturação à $94^{\circ} \mathrm{C}$ por um minuto, anelamento a $60^{\circ} \mathrm{C}$ por dois minutos e amplificação a $72^{\circ} \mathrm{C}$ por um minuto e meio, após uma extensão final a $72^{\circ} \mathrm{C}$ por sete minutos.

$\mathrm{O}$ resultado foi analisado por eletroforese em gel de agarose a $2 \%$ impregando com brometo de etídio e observado sob transluminador de fluorescência. 


\section{RESULTADOS \\ Epidemiologia e sinais clínicos}

Nos meses de novembro/2001 a fevereiro/2002, treze eqüinos desenvolveram sinais clínicos compatíveis com EME, do total de cinqüenta animais. Dos treze animais doentes seis morreram num período de $48 \mathrm{~h}$ após o aparecimento dos sinais de diarréia. A morbidade foi de $26 \%$ e letalidade de $46,1 \%$. Os animais acometidos tinham idades entre um e cinco anos e apresentaram diarréia aquosa e profusa de forma aguda, demonstrando prostação e anorexia. Alguns animais ao locomoverem-se apresentaram a marcha rígida. Os animais doentes foram tratados com oxitetraciclina, administrada via endovenosa, a $6,6 \mathrm{mg} / \mathrm{kg} /$ dia, até demonstrarem melhora dos sinais clínicos.

\section{Patologia}

As alterações observadas à patologia do animal necropsiado são resumidas no Quadro 1.
Macroscopia. Na mucosa do intestino delgado, evidenciaram-se áreas avermelhadas, caracterizadas por congestão e hemorragia, alternadas com áreas de mucosa normais. No duodeno, jejuno e íleo verificou-se a presença de grande quantidade de muco. Na mucosa do jejuno e íleo observaram-se nódulos de até um centímetro de diâmetro, contendo secreção purulenta, que era liberada quando o nódulo era pressionado (Fig.1). Os segmentos do intestino grosso (ceco, cólon maior e cólon menor) apresentaram hemorragia difusa na mucosa com conteúdo fecal aquoso (Fig.2). Nos linfonodos mesentéricos constatou-se aumento de volume e presença de edema. Nos demais órgãos nenhuma alteração macroscópica foi evidenciada.

Microscopia. Em todo trato intestinal, observou-se a presença de um discreto infiltrado inflamatório mononuclear restrito a mucosa do órgão, caracterizando uma enterite linfo-histiocitária com predominância de macrófagos. Na porção final do duodeno,

Quadro 1. Alterações macroscópicas e microscópicas observadas em animal morto por Ehrlichiose monocítica eqüina

\begin{tabular}{|c|c|c|}
\hline Órgão/tecido & Alteração macroscópica & Alteração microscópica \\
\hline Duodeno & Mucosa com áreas hemorrágicas e congestas & Porção final com lesão granulomatosa \\
\hline Jejuno & $\begin{array}{l}\text { Presença de muco na luz intestinal e mucosa com áreas hemorrá- } \\
\text { gicas,congestas e com focos de secreção purulenta }\end{array}$ & $\begin{array}{l}\text { Lesões granulomatosa linfohistiocitária e discreto infiltra- } \\
\text { do de células mononucleares }\end{array}$ \\
\hline Íleo & $\begin{array}{l}\text { Luz intestinal com conteúdo mucoso. Mucosa com áreas hemor- } \\
\text { rágicas com focos de secreção purulenta }\end{array}$ & $\begin{array}{l}\text { Lesões granulomatosa linfohistiocitária e discreto infiltra- } \\
\text { do de células mononucleares }\end{array}$ \\
\hline Ceco & Hemorragia difusa; conteúdo fecal totalmente líquido & Discreto infiltrado mononuclear na mucosa e submucosa \\
\hline $\begin{array}{l}\text { Cólon maior/ } \\
\text { cólon menor }\end{array}$ & Hemorragia difusa presença de conteúdo fecal mucóide e líquido & Discreto infiltrado mononuclear na mucosa e submucosa \\
\hline $\begin{array}{l}\text { Linfonodos } \\
\text { mesentéricos }\end{array}$ & Aumentados de volume e edemaciados & - \\
\hline Baço & Sem alteração evidente & Depleção grave de tecido linfóide, hemossiderose acentuada \\
\hline Fígado & Sem alteração evidente & Degeneração centro lobular \\
\hline Pulmão & Sem alteração evidente & $\begin{array}{l}\text { Pneumonia intersticial subaguda linfohistiocitária multifocal } \\
\text { com hemossiderose discreta }\end{array}$ \\
\hline
\end{tabular}
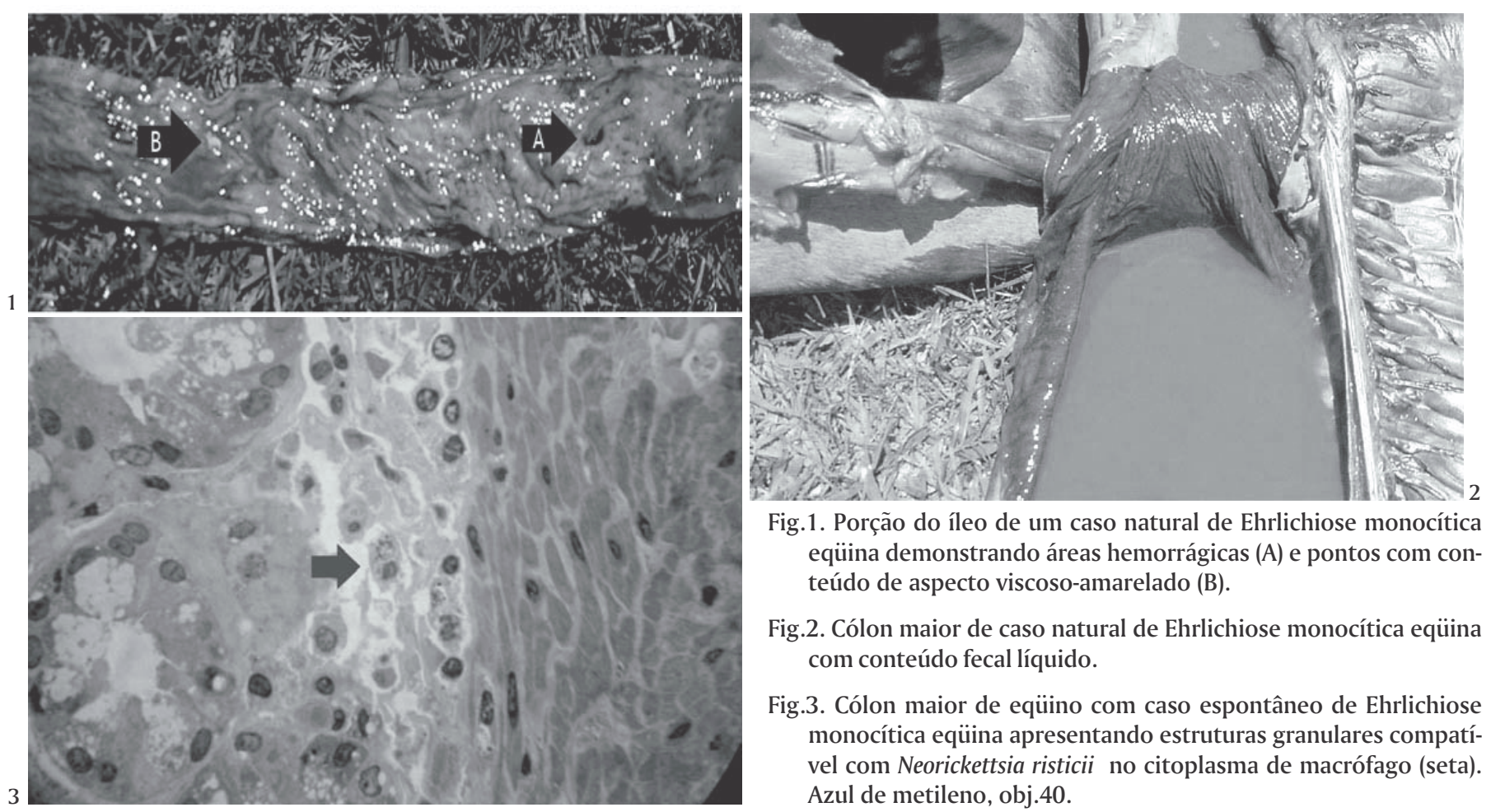

Fig.1. Porção do íleo de um caso natural de Ehrlichiose monocítica eqüina demonstrando áreas hemorrágicas (A) e pontos com conteúdo de aspecto viscoso-amarelado (B).

Fig.2. Cólon maior de caso natural de Ehrlichiose monocítica eqüina com conteúdo fecal líquido.

Fig.3. Cólon maior de eqüino com caso espontâneo de Ehrlichiose monocítica eqüina apresentando estruturas granulares compatível com Neorickettsia risticii no citoplasma de macrófago (seta). Azul de metileno, obj.40. 


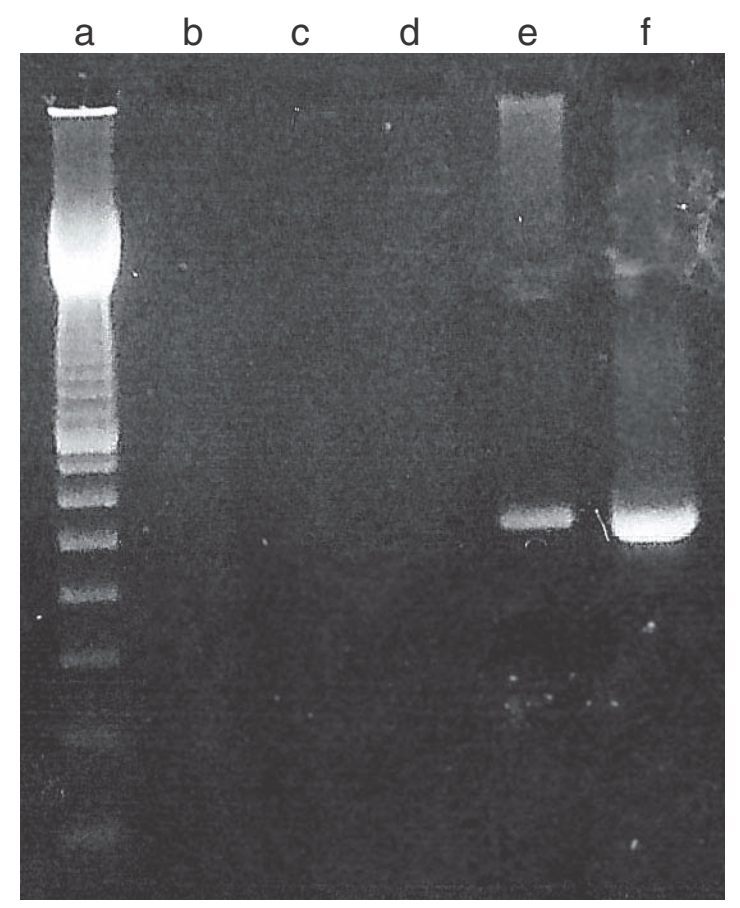

Fig.4. Eletroforese em agarose indicando o produto do PCR de 529pb do DNA da Neorickettsia risticii: (a) marcador de peso molecular de 100 pares de bases; (b) controle negativo; (c,d) cavalos negativos; (e) cavalo positivo; (f) controle positivo. (Amostras coletadas de animais suspeitos de Ehrlichiose monocítica eqüina, em dezembro de 2001).

no jejuno e íleo foram observados pontos com lesões granulomatosas na lâmina própria, relacionadas com invaginação das criptas das vilosidades intestinais. Essas lesões continham restos celulares e calcificação discreta com numerosas colônias bacterianas. No jejuno foi evidenciado ainda um infiltrado inflamatório mononuclear discreto restrito à lâmina própria da mucosa. No cólon e ceco, observou-se a presença de infiltrado inflamatório mononuclear discreto na mucosa e submucosa, caracterizando um processo inflamatório mais intenso com dilatação e congestão dos capilares sanguíneos e edema da submucosa.

Alterações histológicas foram evidenciadas, também, no baço, fígado e pulmão. No baço, foram constatadas depleção grave de tecido linfóide e hemossiderose acentuada. No fígado foi evidenciada degeneração centrolobular e no pulmão foi observada pneumonia intersticial subaguda linfo-histiocitária multifocal com hemossiderose discreta.

Nos cortes histológicos do intestino grosso (ceco e cólon maior) corado com azul de metileno, foram observadas várias estruturas granulares compatíveis com $N$. risticii no interior do citoplasma de macrófagos (Fig.3).

\section{Nested PCR}

Três das sete amostras de sangue coletadas animais doentes resultaram positivas pela técnica de PCR (42,8\%) (Fig.4).

\section{DISCUSSÃO E CONCLUSÕES}

Neste estudo, foram observadas as características endêmica e sazonal, descritas para erliquiose monocítica equina. A proprie- dade estudada localiza-se no município de Arroio Grande, situado ao Sul do Rio Grande do Sul, uma região de baixa altitude e com campos predominantemente alagadiços, em decorrência da proximidade com a Lagoa Mirim. Os casos de EME ocorreram no verão, nos meses de novembro/2001 a fevereiro/2002.

De acordo com Atwill et al. (1994), a EME ocorre de forma endêmica e sazonal, sendo evidenciada em estados americanos localizados adjacentes a rios, vales ou pântanos, como nos Estados de Maryland e Virginia, localizados próximos ao rio Potomac. A tendência sazonal da EME implica em uma ocorrência maior nos meses mais quentes, junho a setembro no hemisfério norte. A prevalência e incidência acompanham a sazonalidade, ou seja, nos meses de fevereiro a maio a prevalência pode variar de $0 \%$ a $10 \%$, enquanto que nos meses de julho e agosto apresentam picos de até 75\% (Goetz et al. 1989, Olchowy et al. 1990, Atwill et al. 1992).

A taxa de letalidade observada neste estudo $(46,1 \%)$ foi superior ao citado na literatura a qual varia entre $5 \%$ a $30 \%$ em cavalos expostos naturalmente, podendo atingir até 36\% (Rikihisa 1998). Deve ser ressaltado que os animais eram criados a campo e a identificação de casos era feita pelos peões. É possível que casos leves não tenham sido percebidos, fato que elevaria a morbidade e reduziria a letalidade do surto. Além disso, existia uma maior suscetibilidade de todo o lote de animais por não apresentarem imunidade prévia à enfermidade uma vez que os animais eram oriundos de uma região livre, sem relato de casos de EME. A região de origem desses animais apresenta característica geográfica diferente, com maior altitude, campos levemente ondulados, típicos da área sul da encosta do Sudeste gaúcho, sem a presença de grandes mananciais de água, embora localizado no mesmo Município. Tem sido demonstrado que animais transportados e introduzidos em áreas endêmicas são mais suscetíveis à doença devido a falta de contato com o agente. (Dutra et al.2001).

No presente trabalho, a maior parte dos eqüinos doentes apresentou idades $=3$ anos, com exceção de um animal que tinha cinco anos. Nos Estados Unidos, a maior incidência de EME ocorre em animais com idade acima de quatro anos, não havendo descrição de casos em potros com menos de um ano (Atwill et al. 1992).

Os achados clínicos foram compatíveis com a enfermidade conforme descrito por outros autores. Os animais com EME podem desenvolver desde a forma subclínica até a forma clínica que varia de leve a severa com a morte de animais, sendo que a diarréia ocorre em cerca de 70\% dos casos (Ziemer et al. 1987).

Com o tratamento com oxitetraciclina utilizado neste estudo, sete animais $(53,8 \%)$ recuperaram-se. Em um estudo experimental 70\% dos cavalos se recuperam em cinco a sete dias após o tratamento com oxitetraciclina quando administrada durante o pico febril, antes do aparecimento da diarréia. Nos casos em que a diarréia já esta presente, o tratamento pode ser mais prolongado e menos eficiente, devido ao estado de debilidade que a doença provoca nos animais (Rikihisa 1998).

Os achados macroscópicos encontrados no equiino necropsiado neste estudo foram similares ao descrito para EME (Cordes et al. 1986). Estes autores relatam como achados mais evidentes o distendimento do colón maior e ceco que se encontram reple- 
tos de conteúdo líquido. As alterações microscópicas observadas nesse estudo apresentaram características semelhantes às relatadas por Cordes et al. (1986) e Dutra et al. (2001). No entanto, na porção final do duodeno, no jejuno e íleo foram observadas lesões granulomatosas na lâmina própria relacionadas com invaginação das vilosidades intestinais, com presença de calcificação e numerosas colônias bacterianas. A ocorrência dessas lesões, em geral, é induzida por alguns tipos de microrganismos ou agentes não infecciosos que são persistentes no tecido (Slauson \& Cooper 1990).

Nos cortes histológicos do trato intestinal corados com azul de metileno, as estruturas intracitoplasmáticas encontradas no interior dos macrófagos são semelhantes com as descritas por Rikihisa et al. (1985) e compatíveis com mórulas de N. risticii.

No baço, a depleção linfóide e hemossiderose intensa encontradas, são alterações ainda não relatadas em eqüinos com EME. Segundo John et al. (1989) em animais jovens a depleção linfóide pode ser observada, mas localizada aos nódulos linfóides do segmento intestinal acometido. Entretanto, cães infectados por Neorickettsia helminthoeca desenvolvem depleção linfóide com degeneração do centro germinativo, devido a grande mobilização de macrófagos que a infecção induz (Rikihisa et al. 1991). As alterações histológicas encontradas no fígado e pulmão podem ter sido em parte, devido a choque endotoxêmico que pode ocorrer pela penetração de bactérias gram negativas na mucosa intestinal lesada ou por outra causa concomitante não determinada.

A Nested PCR identificou $42,8 \%$ das amostras como positivas, embora todos os cavalos testados neste estudo apresentassem sinais clínicos. Alguns animais já haviam sido tratados com antibiótico antes da coleta das amostras de sangue, o que pode ter influenciado na sensibilidade da técnica. Segundo Barlough et al. (1997) e Mott et al. (1997), a PCR é capaz de detectar 81\% das amostras clínicas.

Pode-se concluir que a EME ocorre no Rio Grande do Sul, em regiões com características geográficas específicas e em épocas quentes, podendo ocasionar alta taxa de letalidade quando animais são introduzidos em área endêmica. A enfermidade produz, clinicamente, diarréia aquosa que pode ser de forma aguda e grave levando a morte dos animais em até $48 \mathrm{~h}$ após o início dos sinais clínicos. As alterações patológicas do trato intestinal caracterizam-se como enterite linfo-histiocitária segmentar.

\section{REFERÊNCIAS}

Atwill E.R., Mohammed H.O. \& Rua-Domenech R. 1994. Geographical variation of seropositivity to Ehrlichia risticii (Equine monocytic ehrlichiosis) of horses in New York State. Equine Vet. J. 26 (2):143-147.

Atwill E.R., Mohammed H.O., Dubovi E. \& Lopes J. 1992. Retrospective evaluation of factors associated with the risk of seropositivity to Ehrlichia risticii in horses in New York state. Am. J. Vet. Res. 53 (10):1931-1934.

Barlough J.E, Rikihisa Y. \& Madigan J.E. 1997. Nested polymerase chain reaction for detection of Ehrlichia risticii genomic DNA in infected horses. Vet. Parasitol. 68:367-373.

Barlough J.E., Reubel G.H., Madigan J.E., Vredevoe L.K., Miller P.E. \& Rikihisa Y. 1998. Detection of Ehrlichia risticii, the agent of Potomac horse fever, in freshwater stream snails (Pleuroceridae: Juga spp.) from Northern California. Appl. Environ. Microbiol. 64 (4):2888-2893.

Breider M.A. \& Henton J.E..1987. Equine monocytic ehrlichiosis (Potomac Horse Fever). Equine Practice 9:20-24.
Coimbra H.S., Schuch L.F., Riet-Correa F., Curcio B.R., Raffi M.B., Dellagostin O., Mello D.F.M. \& Haag R. 1999. Diarréia em eqüinos causada por Ehrlichia risticii no Sul do Brasil. Anais XIV Congresso Estadual de Medicina Veterinária, II Congresso de Medicina Veterinária do Cone Sul, Gramado, RS, vol.1, p.200.

Coimbra H.S. 2003. Erliquiose monocítica eqüina no Rio Grande do Sul: aspectos clínicos, anátomo-patológicos e epidemiológicos. Dissertação de Mestrado, Programa de Pós-Graduação em Medicina Veterinária, Faculdade de Veterinária, Universidade Federal de Pelotas. 49p.

Cordes D.O., Perry B.D., Rikihisa Y. \& Chickering W.R. 1986. Enterocolitis caused by Ehrlichia sp. in the horse (Potomac horse fever). Vet. Pathol. 23:471-477.

Dumler J.S., Barbet A.F., Bekker C.P.J., Dasch G.A., Palmer G.H., Ray S.C., Rikihisa Y. \& Rurangirwa F.R. 2001. Reorganization of in the families Rickettsiaceae and Anaplasmataceae in order Rickettsiales: Unification of some species of Ehrlichia and Ehrlichia with Neorickettsia, descriptions of six new species combinations and designation of Ehrlichia equi and 'HE agent' as subjective synonyms of Ehrlichia phagocytophila. Int. J. Syst and Evolut. Microbiol. 51:2145-2165.

Dutra F., Schuch L.F.D., Delucchi E., Curcio B. R., Coimbra H.S., Raffi M. B. Dellagostin O. \& Riet-Correa F. 2001. Equine monocytic ehrlichiosis (Potomac horse fever) in horses in Uruguay and southern Brazil. J. Vet. Diagn. Invest. 13:433-437.

Goetz T.E., Holland J.C., Dawson J.E., Ristic M., Skibbe K., Keegan K.G., Johnson P.J., Schaeffer D.J. \& Baker G.J. 1989. Monthly prevalence (in 1986) of antibody titers against equine monocytic ehrlichiosis in apparently healthy horses in Illinois. Am. J. Vet. Res. 50 (11):1936-1939.

Jonh G.A., Van Kruiningen H.J., Reim D. \& Wachtel A.W. 1989. Fatal Potomac horse fever (Ehrlichial colitis) in foal: A case report from Connecticut. J. Equine Vet. Sci. 9 (5):250-252.

Kanter M., Mott J., Ohashi N., Fried B., Reed S., Lin Y.C. \& Rikihisa Y. 2000. Analysis of $16 \mathrm{~S}$ rRNA and 51-Kilodalton antigen gene and transmission in mice of Ehrlichia risticii in virgulate trematodes from Elimia livescens snails in Ohio. J. Clin. Microbiol. 38 (9):3349-3358.

Mott J., Rikihisa Y., Zhang Y., Reed S.M. \& Yu C.Y. 1997. Comparison of PCR and culture to the indirect fluorescent-antibody test for diagnosis of Potomac horse fever. J. Clin. Microbiol. 35(9):2215-2219.

Olchowy T.W.J., James T.R. \& Molitor T.W. 1990. Serodiagnosis of equine monocytic ehrlichiosis in selected groups of horses in Minnesota. J. Am. Vet. Med. Assoc. 196(12):1967-1970.

Palmer J.E., Whitlock R.H. \& Benson C.E. 1986. Equine ehrlichial colitis (Potomac horse fever): Recognition of the disease in Pennsylvania, New Jersey, New York, Ohio, Idaho and Connecticut. J Am. Vet. Med. Assoc. 189:197-199.

Pusterla N., Madigan J.E., Chae J.-S., DeRock E., Johnson E. \& Pusterla J.B. 2000. Helminthic transmission and isolation of Ehrlichia risticii, the causative agent of Potomac horse fever, by using trematode stages from freshwater stream snails. J. Clin. Microbiol. 38(3):1293-1297.

Rikihisa Y. \& Perry B.D. 1985.Causative Ehrlichial organisms in Potomac horse fever. Infect. Immun. 49 (3):513-517.

Rikihisa Y. 1998. Rickettsial diseases, p.112-123. In: Ibid. (ed.) Equine Internal Medicine. W.B. Saunders Company, Philadelphia, USA.

Rikihisa Y., Stills H. \& Zimmerman G. 1991. Isolation and continuous culture of Neorickettsia helminthoeca in macrophage cell line. J. Clin. Microbiol. 29(9):1928-1933.

Slauson D.O. \& Cooper B.J. 1990. Mechanisms of Diseases. 2nd edition. Williams \& Wilkins, Baltimore, USA. 540p.

Wen B., Rikihisa Y., Yamamoto S., Kawabata N. \& Furest P.A. 1996. Characterization of the SF agent, an Ehrlichia sp isolated from the fluke Stellantchasmus falcatus by $16 \mathrm{~S}$ rRNA base sequence serological and morphological analyses. Int. J. Syst. Bacteriol. 46:149-154.

Ziemer L.E., Whitlock R.H., Palmer J.E. \& Spencer P.A. 1987. Clinical and hematological variables in ponies with experimental induced equine ehrlichial colitis (Potomac horse fever). Am. J. Vet. Res. 48:63-67. 